\title{
Model desain taman ramah anjing Pomeranian
}

\author{
Krisna Dinata Cendana, Naniek Kohdrata*, Anak Agung Gede Sugianthara \\ Program Studi Arsitektur Pertamanan, Fakultas Pertanian, Universitas Udayana, Indonesia \\ *E-mail: naniek_kohdrata@unud.ac.id
}

\begin{abstract}
Pomeranian-friendly park design. Pomeranian is one of the small dog breeds that has an attractive appearance and characteristics. Pomeranian dog lovers population in Bali has been growing rapidly since 2008 until 2017. It is recorded that the number of pomeranian breeders is 1.246 of 2.370 breeders (Perkin Bali, 2017). Pomeranian-friendly park design is created as, resting and activities area for dogs within a garden setting. It also can function as a training, socializing and playing place for pomeranian. purpose of study is to utilize the park as a supporter of pomeranian activities that affect physical and mental growth. The design of this park includes elevation, and selection of softscape hardscape materials, design of prototype objects so as to support the security and comfort of pomeranian. The research method using qualitative method of observation, interviewing and literature based. The concept of this design providing pomeranian activity space such as playing space, shade space, rest area, training area, gromming area, also put into consideration the comfort of dog owners as a park user as well as guests who visit with a space planning called cozy area where in that area park users can discuss while relaxing enjoy the view of the garden from the top floor which is the best angle when viewing the garden atmosphere which has iconic landmarks in the form of pavilion-shaped icon pomeranian and a variety of plants that have accents and contrast effects as a visual pleasure.
\end{abstract}

Keywords : pomeranian, theme park, dog friendly park.

\section{Pendahuluan}

Pomeranian memiliki anatomi proposional yang menjadi daya tarik bagi para penggemar anjing. Kesehatan serta karakter anjing dipengaruhi oleh berbagai macam faktor antara lain makanan, kondisi lingkungan, perawatan, kebutuhan sosial, dan pelatihan.

Populasi pecinta anjing pomeranian yang tinggi di Bali menjadi acuan untuk melakukan penelitian ini. Data dari Perkumpulan Kinologi Indonesia (PERKIN) daerah Bali bahwa terdapat 1.264 dari total 2.370 pembiak dengan persentase sebesar $53.3 \%$. Jumlah populasi pecinta anjing ras pomeranian merupakan target pengguna taman yang potensial sehingga mendesain sebuah taman yang menarik dan bermanfaat bagi pemelihara anjing pomeranian menjadi latar belakang ide penelitian ini.

Keterlibatan taman dalam memenuhi kebutuhan pomeranian diaplikasikan lewat ruang aktivitas pomeranian berupa ruang umbar untuk memfasilitasi aktivitas bermain dan bersosialisasi anjing pomeranian dan ruang pelatihan sebagai tempat mereka dilatih oleh pengguna taman. Kriteria mengenai hal-hal yang memenuhi kebutuhan kenyamanan dan keamanan pomeranian menciptakan suatu karakter yang sehat secara fisik maupun mental dapat diintegrasikan melalui taman khusus. Desain taman ini tentu perlu juga mempertimbangkan kenyamanan manusia sebagai pengguna taman, yaitu para pemilik anjing.

Rumusan masalah pada penelitian ini karakter anjing pomeranian dan kriteria taman seperti apa yang memenuhi syarat ramah anjing pomeranian. Tujuan dari penelitian ini adalah mengetahui karakter anjing pomeranian dan membuat model taman yang menunjang atau mendukung keamanan dan kenyamanan anjing pomeranian.

\section{Metode Penelitian}

\subsection{Lokasi dan Waktu Penelitian}

Desain model taman tematik yang direncanakan dalam penelitian ini memanfaatkan sebidang lahan yang terletak di Desa Baturiti, Kecamatan Baturiti, Kabupaten Tabanan, Bali. Kondisi tapak berupa lahan 
kosong dengan luasan $600 \mathrm{~m} 2$. Penelitian dilaksanakan selama 12 bulan mulai bulan Desember 2016 sampai dengan bulan Desember 2017.

\subsection{Metode Penelitian}

Penelitian dilakukan dengan metode kualitatif dengan metode analisa deskriptif (Yusuf. 2014). Dimulai dengan tahapan inventarisasi data yakni mengumpulkan data yang ada dan diperlukan mengenai tapak yang akan didesain untuk anjing pomeranian. Kemudian dilanjutkan dengan analisis data yakni memilah data yang terkumpul sehingga dapat diketahui permasalahan dan kebutuhan pomeranian saat beraktivitas di taman, dan sintesis dengan menyusun penyelesaian masalah untuk menghasilkan konsep yang merupakan landasan dalam pembuatan desain sehingga menghasilkan model desain.

\subsubsection{Teknik Pengumpulan Data}

Pengumpulan data dilakukan dengan observasi, wawancara, dan studi pustaka.

1. Observasi

Observasi merupakan teknik pengumpulan data dengan melakukan pengamatan secara langsung kondisi tapak dan anjing pomeranian.

2. Wawancara

Wawancara merupakan teknik pengumpulan data dengan mengadakan tanya jawab langsung terhadap pihak-pihak yang berkaitan dengan penelitian yakni ketua umum Perkumpulan Kinologi Indonesia Daerah Bali dan Prof. Dr. Drh I Ketut Puja, M Kes. mengenai hal-hal yang berkaitan dengan karakteristik, permasalahan, dan kebutuhan pomeranian.

\section{Kepustakaan}

Kepustakaan, yaitu teknik pengumpulan data yang diperoleh dengan cara membaca dan mempelajari literatur-literatur, jurnal, internet, catatan kuliah dan sumber-sumber lain yang relevan dengan masalah yang diteliti.

\subsubsection{Indeks Kenyamanan}

Indeks kenyamanan dapat ditentukan dari hasil pengukuran temperatur dan kelembaban udara pada setiap lokasi penelitian menggunakan rumus Nieuwolt (1998) sebagai berikut:

$$
\begin{aligned}
& \mathrm{IK}=0,8 \mathrm{~T}+(\mathrm{RH} \times \mathrm{T}) / 500 \text {. } \\
& \text { Keterangan: } \\
& \text { IK = Indeks Kenyamanan } \\
& \mathrm{T} \quad=\text { Temperatur rata-rata } \\
& \mathrm{RH}=\text { Kelembaban rata-rata }
\end{aligned}
$$

\subsection{Batasan Penelitian}

Penelitian ini berfokus pada karakteristik fisik dan perilaku anjing pomeranian dengan cara meninjau dan menganalisa karakteristik tersebut, sehingga muncul kelemahan dan kebutuhan pomeranian saat beraktivitas di taman. Tujuan penelitian ini adalah untuk mendasari pembuatan suatu model taman yang menunjang kenyamanan dan keamanan anjing pomeranian saat beraktivitas pada taman. Hasil dari penelitian ini adalah konsep desain taman yang diwujudkan dalam model desain ramah anjing pomeranian.

\section{Hasil dan Pembahasan}

\subsection{Kondisi Umum Tapak Penelitian}

Tapak terletak di Kecamatan Baturiti yang merupakan kawasan yang memiliki suhu relatif sejuk. Pemilihan kawasan ini merupakan salah satu faktor pendukung kenyamanan manusia sebagai pengguna taman. Fluktuasi suhu udara dalam satu tahun di lokasi penelitian dan sekitarnya berkisar antara $25.4-27.6^{\circ} \mathrm{C}$, dengan suhu maksimum tertinggi sebesar $33^{\circ} \mathrm{C}$, dan suhu minimum terendah sebesar $20.2^{\circ} \mathrm{C}$ (AccuWeather, 2016). Sedangkan rata-rata kelembaban udara di kawasan ini berkisar antara $87-90 \%$ dengan kelembaban tertinggi 90\% (Tabel 1). 
Tabel 1. Rata-Rata Suhu Udara Kecamatan Baturiti tahun 2016

\begin{tabular}{llcccc}
\hline No & Bulan & $\begin{array}{c}\text { Suhu Rata- } \\
\text { rata }\left({ }^{\circ} \mathrm{C}\right)\end{array}$ & $\begin{array}{c}\text { Suhu } \\
\text { Tertinggi }\left({ }^{\circ} \mathrm{C}\right)\end{array}$ & $\begin{array}{c}\text { Suhu } \\
\text { Terendah } \\
\left({ }^{\circ} \mathrm{C}\right)\end{array}$ & $\begin{array}{c}\text { Kelembaban } \\
(\%)\end{array}$ \\
\hline 1 & Januari & 27.4 & 32 & 22.8 & 88 \\
2 & Februari & 27.4 & 31.9 & 23 & 87 \\
3 & Maret & 27.6 & 32.2 & 23 & 87 \\
4 & April & 27.5 & 32.8 & 22.2 & 87 \\
5 & Mei & 26.6 & 31.2 & 22 & 87 \\
6 & Juni & 26 & 31.1 & 20.9 & 89 \\
7 & Juli & 25.4 & 30.7 & 20.2 & 90 \\
8 & Agustus & 25.8 & 30 & 21.6 & 89 \\
9 & September & 27 & 32 & 22 & 89 \\
10 & Oktober & 26.9 & 31.8 & 22 & 88 \\
11 & November & 27.5 & 33 & 22 & 88 \\
12 & Desember & 27.1 & 32.2 & 22 & 87 \\
& Rata-rata & 26.8 & 31.8 & 21.9 & 88 \\
\hline
\end{tabular}

Sumber: AccuWeather (2016)

Data tersebut memperlihatkan bahwa kawasan tapak memiliki suhu yang relatif dingin dan lembab sepanjang tahun. Hal tersebut menjadi suatu faktor pendukung terkait kenyamanan pengguna taman.

\subsection{Karakteristik Pomeranian}

Pomeranian berasal dari nama sebuah provinsi di Jerman. Pomeranian adalah tipikal anjing yang lucu, penuh semangat, cerdas dan bersahabat (Gambar 2). Pomeranian memiliki tinggi 17 sampai 30 centimeter dan beratnya 3 sampai 7 kilogram.

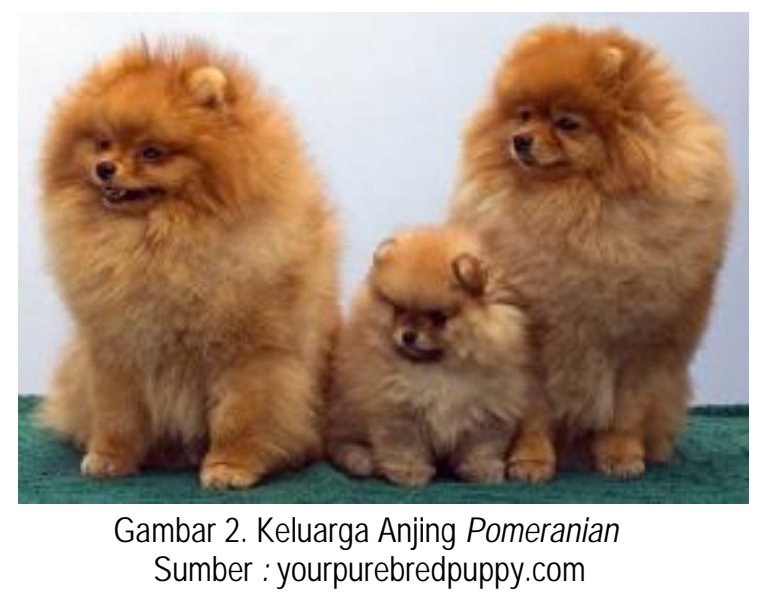

Fisik dan mental pomeranian dipengaruhi oleh sejumlah faktor seperti genetik, perawatan, pelatihan dan kebutuhan sosial. Anjing pomeranian yang memiliki kondisi fisik dan mental yang baik bisa dilihat dari keaktifan mereka dalam beraktivitas, expresi wajah, dan anatomi tubuh mereka.

\subsection{Perawatan Pomeranian}

Pemeliharaan pomeranian bukan hal sulit, namun tetap membutuhkan beberapa perlakuan khusus terkait perawatan. Beberapa hal yang perlu mendapat perhatian adalah tubuh yang kecil, bulu lebat, tempurung lutut yang rentan, dan persendian lemah menjadi suatu pertimbangan perhatian khusus dalam pemeliharaan agar anjing pomeranian terhindar dari cedera maupun hal buruk lainnya.

Bulu panjang dan tebal seperti anjing pomeranian harus sering disisir. karena pomeranian memiliki dua jenis bulu (double-coat) yang sangat mudah kusut dan menggumpal. Penyebab dari bulu kusut biasanya adalah bulu basah yang terjadi karena beberapa hal seperti liur anjing, urin anjing, dan makanan. Penyebab 
lain adalah kerontokan bulu. Saat musim kerontokan bulu pomeranian, umumnya bulu kapasnya mengalami kerontokan yang lebih besar dibandingkan dengan bulu jarumnya sehingga penggumpalan bulu akan terjadi jika bulu-bulu mati yang telah rontok tidak disisir (Richang, 2017).

Pomeranian termasuk golongan toy group bermoncong pesek yang mudah mengalami kepanasan dan sulit untuk menurunkan suhu tubuhnya karena panas terik matahari. Ketika pomeranian berada di luar ruangan untuk dijemur, maka perhatian ekstra perlu diberikan untuk mengetahui tanda-tanda kepanasan seperti nafas yang lebih cepat dan lidah yang menjulur (Puja. 2017). Heat Stroke umumnya mudah menyerang anjing. Suhu tubuh anjing lebih tinggi daripada suhu tubuh manusia dan kemampuan untuk menurunkan suhu tubuh lebih rendah dari pada manusia karena manusia bisa mengeluarkan keringat untuk menurunkan suhu tubuh, sedangkan anjing menurunkan suhu tubuhnya hanya dari hidung, mulut, dan pori-pori dibawah telapak kakinya saja (Zhang, 2015). Anjing yang memiliki moncong pendek atau pesek seperti anjing shihtzu, pekingese, pomeranian, pug, bulldog, dan boxer akan lebih cepat terserang kepanasan dan sulit untuk menurunkan suhu tubuhnya (Zhang, 2015).

Tempurung lutut dan persendian pomeranian merupakan bagian badan yang sangat rentan cedera, Kasus seperti fraktur yang disebabkan oleh terjatuh dari tempat yang tinggi adalah jenis-jenis cedera yang rentan dialami. Pomeranian adalah anjing yang aktif oleh sebab itu, untuk mencegah terjadinya cedera sebaiknya hindari anjing pomeranian dari tempat-tempat yang tinggi (Puja. 2017). Fraktur merupakan patahnya tulang yang biasanya dialami anjing kecil akibat kecelakaan, terjatuh, dan luka. Tulang memiliki bahan yang mempunyai daya elastisitas sehingga jika trauma lebih besar daripada daya elastisitasnya maka akan terjadi fraktura. Tanda klinis yang terjadi pada fraktur adalah kebengkakan, deformitas, kekakuan gerak yang abnormal, kehilangan fungsi dan rasa sakit (Kumar. 1997).

\subsection{Permasalahan Lingkungan}

Salah satu dampak negatif adalah pencemaran udara yang dapat disebabkan oleh anjing pomeranian adalah bau urin dan bulu yang berterbangan. Urin berpotensi membuat lingkungan berbau tak sedap, begitu pula dengan bulu yang berterbangan memiliki dampak penurunan kualitas udara. Pencemaran udara oleh bulu pomeranian terjadi pada saat masa kerontokan bulu dan hal ini akan sangat mengganggu pernafasan manusia yang beraktivitas di dalam lingkungan tersebut.

\subsection{Sintesis}

Beberapa kasus pemeliharaan dapat menyebabkan dampak buruk yang cukup fatal bagi pomeranian. Pemecahan masalah untuk mengatasi kerentanan pomeranian maupun membentuk dan meningkatkan potensi baik anjing tersebut dapat dilakukan dengan aplikasi fasilitas dan material yang sesuai lingkungan, perawatan, dan pelatihan. Desain taman diselaraskan dengan keperluan pomeranian terhadap ketinggian, suhu udara/paparan sinar matahari, dan kondisi bulu. Desain taman nantinya juga perlu mengatasi dampak yang ditimbulkan oleh anjing pomeranian pada manusia, yaitu bau urin dan bulu-bulu rontok.

Selain itu, elevasi juga mempengaruhi kebutuhan lingkungan bagi anjing pomerian. Anjing jenis ini memiliki kelemahan mudah cedera pada kaki sehingga faktor ketinggian merupakan pembatas dalam desain. Elevasi dalam desain taman sebaiknya dibuat dalam rentang 0-80 centimeter.

Untuk faktor iklim mikro, kepekaan pomeranian pada suhu dan paparan panas sinar matahari sementara sinar matahari pagi juga diperlukan untuk pertumbuhannya yang baik menuntut mobilisasi dan pengaturan yang efisien. Area umbar pomeranian perlu disediakan dan secara fungsional juga memiliki fleksibilitas untuk pengelolaan keteduhan (intensitas paparan sinar matahari) sehingga kondisi suhu optimal dapat diupayakan. Area umbar yang fleksibel diperlukan untuk memenuhi kebutuhan sinar matahari yang cukup dan juga waktu sosialisasi bagi pomeranian.

Sedangkan untuk cemaran partikel padat, pomeranian memiliki kepekaan dalam hal perawatan bulu. Selain itu, permasalahan bulu anjing ini juga memberikan dampak lingkungan, terutama manusia. Kebutuhan penyisiran dan pengeringan bulu pomeranian sebelum memasuki kandang adalah hal krusial. Sementara dari proses tersebut tidak dapat dihindari munculnya residu bulu bekas penyisiran. Pada saat musim kerontokan bulu, maka volume bulu yang rontok akan bertambah drastis. Bulu anjing pomeranian relatif ringan sehingga sangat mudah di terbangkan angin. Hal ini diatasi dengan menyediakan tempat khusus dalam ruangan untuk fungsi penyisiran dan pengeringan sehingga pencemaran udara di ruang luar dapat dihindari. 
Permasalahan lainnya yaitu cemaran bau, bagi manusia urin anjing merupakan kendala karena berpotensi untuk menimbulkan cemaran bau. Sementara dari sisi anjing, bau urin merupakan penanda tempat dan sekaligus petanda area aman sehingga akan selalu menjadi rujukan untuk melakukan hal yang sama di tempat tersebut. Pada saat diumbar anjing pomeranian sangat berpotensi untuk buang air kecil secara sembarang. Hal ini dapat dihindari dan dikurangi dengan membuat suatu titik tertentu di ruang umbar yang memiliki pemicu untuk memancing anjing untuk buang air kecil pada tempat tersebut. Fungsi fasilitas ini untuk mencegah atau mengurangi potensi buang air sembarang. Fasilitas ini juga memperkecil resiko pomeranian terkena urin yang berpotensi merusak bulu pomeranian. Persoalan cemaran bau bagi manusia dapat diatasi dengan memanfaatkan tanaman yang mengeluarkan bau harum sebagai penetralisir/pengurangan bau urin. Hal ini didukung dengan hasil perhitungan data suhu udara nilai indeks kenyamanan sebesar 26,1 yang dikategorikan sebagai kawasan yang nyaman (Nieuwolt. 1998)

\subsection{Konsep Desain}

Pemodelan taman tematik bagi anjing pomeranian mengusung konsep desain yang mempertimbangkan kelemahan dan kebutuhan khusus anjing pomeranian. Pendekatan desain dilakukan melalui rekayasa fasilitas dan pilihan kategori tanaman. Penerapan konsep desain pada lokasi tapak ini adalah konsep taman tematik yaitu pom facillities yang terdiri dari zonasi tapak, konsep tata ruang, konsep sirkulasi, konsep perkerasan, konsep pencahayaan, konsep penanaman dan model objek berdasarkan analisa dan sintesis anjing pomeranian.

Konsep ini memberikan fasilitas yang menunjang anjing untuk menjadi lebih terlatih, lebih mengkondisikan keamanan fisik maupun mental. Konsep ini dibuat untuk mendukung kebutuhan kenyamanan dan keamanan pomeranian.

Zonasi Tapak dibagi atas beberapa zona untuk memenuhi fungsi taman sebagai tempat yang dapat memfasilitasi perawatan dalam perkembangan pomeranian serta memberikan pula manfaat kenyamanan manusia sebagai pengguna taman. Zonasi tapak ruang terdiri dari beberapa blok ruang yaitu zona rawat, zona istirahat, zona tampil, zona aktivitas, dan zona selamat datang

Tata ruang terbentuk atas dasar berbagai kebutuhan pomeranian lewat media taman, berupa susunan ruang yang memiliki karakter dan maanfaatnya masing-masing bagi pomeranian. Desain konsep tata ruang terdiri dari 12 ruang dengan karakteristik masing-masing dan fungsi umum maupun spesifik yang melibatkan pomeranian maupun pengguna taman

Konsep Sirkulasi pada tapak terdiri dari sirkulasi manusia dan kendaraan. Pergerakan manusia terdireksi oleh ruang-ruang yang telah terbangun dengan media jalan setapak. Sirkulasi manusia dapat berupa jalan setapak maupun jalur yang dapat dilalui yang membentuk hubungan erat dengan aktivitas kegiatan di dalam tapak. Sirkulasi kendaraan hanya sebatas keluar masuk area parkir.

Konsep perkerasan pada area parkir menggunakan material yang memiliki daya serap air. Pertimbangan penggunaan material ini untuk keamanan kendaraan agar tidak mudah tergelincir. Perkerasan pada jalan setapak mengutamakan material yang memiliki fungsi keamanan dan estetika yang kuat untuk member nilai visual positif pada taman.

Konsep pencahayaan pada tapak didesain untuk aspek fungsional dan dekoratif. Instalasi pencahayaan fungsional harus dapat memenuhi fungsi keamanan untuk aktivitas pada malam hari. Pecahayaan dekoratif sebagai kepentingan estetika visual yang diaplikasikan pada ruang pamer.

Konsep Penanaman pada model desain taman ramah pomeranian ini memberikan beberapa rekomendasi tanaman untuk kawasan tapak yang berada di dataran rendah dan dataran tinggi karena pengaplikasiannya perlu melihat setiap karakteristik tanaman yang akan dipakai dan memiliki fungsi pada tipikal kawasan masing-masing. Tanaman yang dipakai pada model desain ini secara general bisa diaplikasikan pada kawasan dataran tinggi dan dataran rendah memiliki aspek fungsional yaitu teduh dan aroma, aspek estitikanya yaitu dekoratif.

\subsection{Model Objek}

Objek trigger terinspirasi dari pet dispenser yang diciptakan oleh Patricia Akens, Harold Bennett, dan Larry Gelfond. Objek ini dirancang sebagai objek pemicu anjing pomeranian agar buang air kecil pada titik atau 
tempat yang ditentukan. Keberadaan objek ini memiliki tujuan dalam penurunan tingkat buang air kecil secara sembarang (Gambar 3).

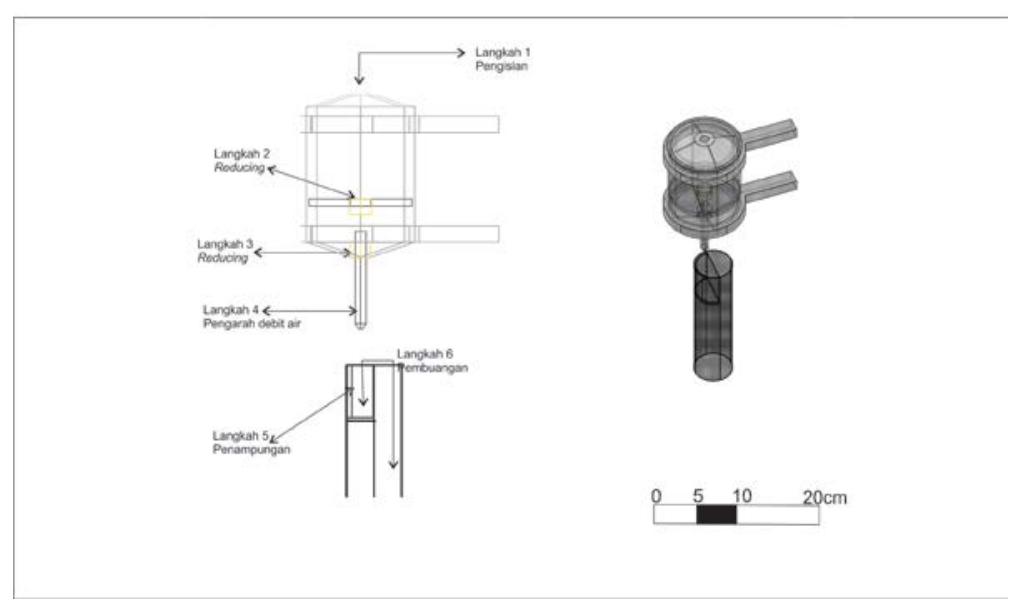

Gambar 3. Ilustrasi Cara Kerja Objek Trigger

Kandang dorong dibuat serupa pagar sebagai pembatas ruang pada ruang umbar pomeranian, objek ini teradaptasi oleh pagar dorong yang memiliki roda dan lining relnya berfungsi untuk memudahkan pemindahan kandang. Ketinggian kandang dorong menyesuaikan kemudahan dalam mengambil atau menaruh pomeranian pada area umbar dan menyesuaikan jangkauan loncatan pomeranian agar tidak bisa menjangkau ketinggian kandang. Instalasi roda pada kandang umbar memiliki tujuan efisien terkait waktu dan tenaga, dengan adanya roda pada kandang umbar mempermudah pemindahan pomeranian dari area umbar ke area teduh (Gambar 4).

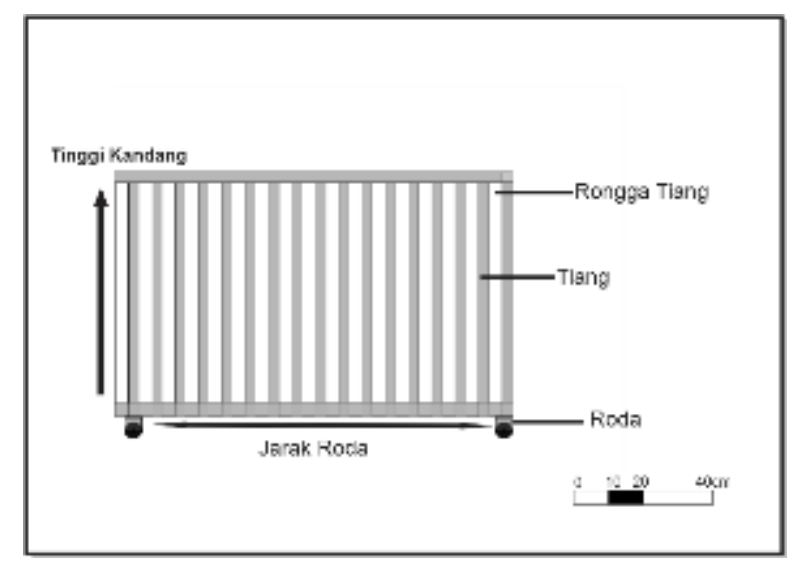

Gambar 4. llustrasi Kandang Dorong

\subsection{Model Desain Taman Ramah Pomeranian}

Desain taman ramah anjing pomeranian menyajikan kenyamanan, keamanan, untuk anjing pomeranian dan kenyamanan, keamanan, keindahan untuk pengguna taman lewat model bentuk taman dan fasilitas yang teraplikasi pada taman. Desain ini dirancang sedemikian rupa agar dapat diandalkan dalam pencegahan terjadinya pengaruh buruk terhadap pomeranian, pengguna taman, maupun lingkungan. Model taman ini sangat memprioritaskan material hardscape dan model objeknya sebab hal itu mempengaruhi Keramahan taman yang diperuntukan anjing pomeranian.

Model taman ini terdiri dari ruang-ruang khusus yang setiap ruang memiliki fungsi dan manfaatnya masing-masing. Kapasitas ruang parkir menyediakan luas yang cukup untuk 3 mobil dan 5 sepeda motor. Desain ruang parkir didasari ketentuan dimensi ukuran untuk jenis mobil mini bus, sedan dan jeep. Pengaplikasian jalan setapak memakai material batu andesit untuk tujuan manfaat keamanan dan estetika 
pada tapak. Batu andesit dibentuk asimetris dengan peletakan yang dibuat sengaja mengikuti ruang aktivitas. Ruang pamer didesain sebagai focal point taman ini karena diantaranya terdapat banyak tanaman yang memiliki tinggi, bentuk, dan keindahan yang variatif. Ruang umbar adalah ruang dimana pomeranian beraktivitas. Ruang umbar disediakan sebagai penunjang aktivitas agar pomeranian bisa bermain dan bersosialisasi dengan yang lainnya. Ruang teduh merupakan ruang pengalihan dari ruang umbar. Fungsi ruang ini sama dengan ruang umbar sebagai ruang aktivitas anjing. Ruang Latih adalah ruang tempat melatih pomeranian. Pelatihan pomeranian secara umum memiliki dua tipe latihan yaitu untuk Show dan Agility.Ruang istirahat adalah ruang peristirahatan pomeranian yang sering disebut kandang pomeranian. Desain dibuat dengan mempertimbangkan dimensi luasan kandang, tinggi kandang, lubang pijakan kaki, dan materialnya. Lubang pijakan kaki dibuat sebagai lubang tempat urin mengalir ke penampungan urin.Ruang rawat adalah suatu ruang yang memfasilitasi pomeranian dalam perawatan bulu berupa punyisiran dan pengeringan bulu. Ruang grooming adalah ruang untuk memandikan pomeranian. Ruang ini memiliki manfaat umum bagi pomeranian. Cozy enterance adalah ruang yang sifatnya sebagai gerbang menuju portal ruang santai. Cozy enterance dibuat untuk membatasi ruang parkir dengan portal ruang santai. Cozy area adalah ruang yang disediakan khusus untuk pengguna taman. Ruang ini berada di bagian atas ruang teduh, ruang ini digunakan sebagai ruang diskusi sesama breeder, komunitas pomeranian, dan tamu lainnya. Ruang ini juga dimanfaatkan untuk bersantai, menikmati pemandangan area pamer.

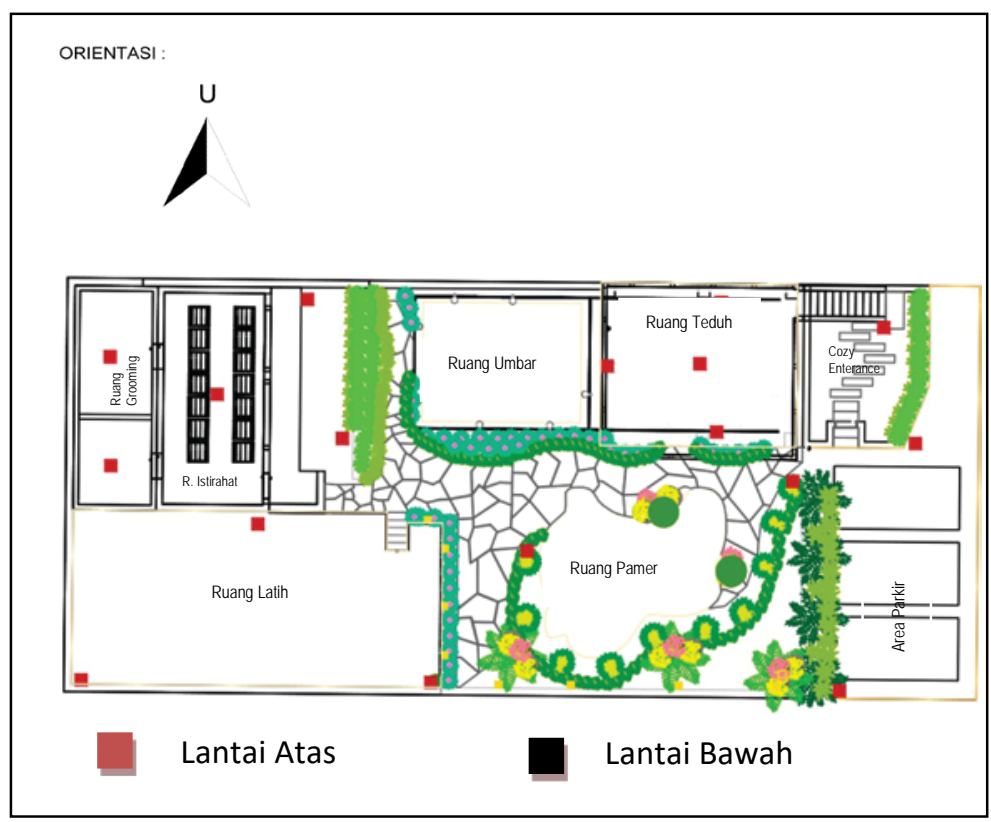

Gambar 5. Model Desain Taman Ramah Anjing Pomeranian

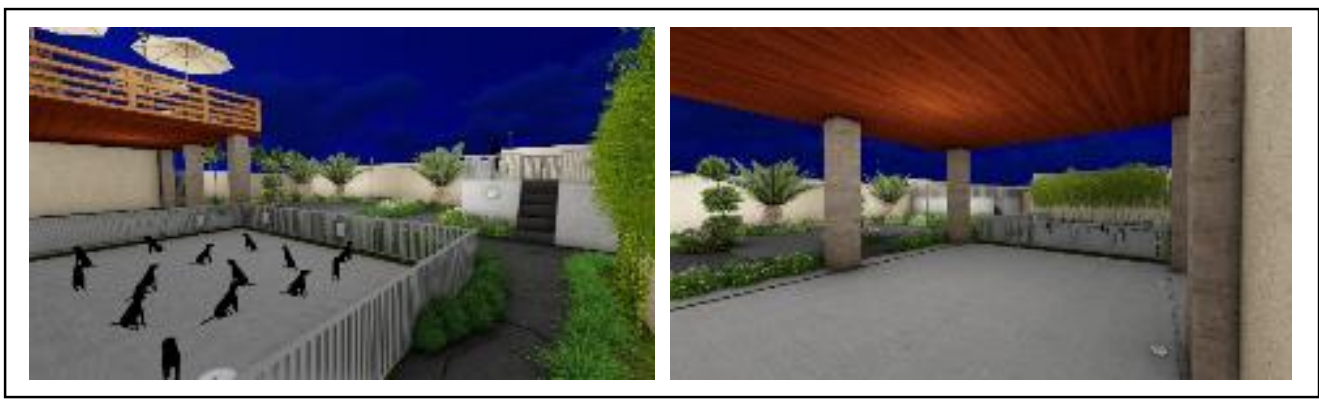

Gambar 6. Ilustrasi Model Desain Taman Ramah Anjing Pomeranian 


\section{Simpulan dan Saran}

\subsection{Simpulan}

Anjing ras pomeranian merupakan jenis anjing yang rentan terhadap kondisi tertentu yang bisa ditinjau dari karakteristiknya seperti tubuh kecil, moncong pesek, dan bulu lebat sehingga perlu adanya suatu pemikiran khusus dalam mendesain suatu taman untuk menunjang kenyamanan dan keamanan pomeranian. Pomeranian rentan terhadap ketinggian tempat karena mereka memiliki daya elastisitas tulang yang rendah, resistensi terhadap panas yang rendah, dan bulu yang sangat mudah kusut.

Model desain ini berupa ruang-ruang aktivitas pomeranian berupa ruang umbar, teduh, latih, rawat, grooming, dan istirahat sebagai kebutuhan spesifik pomeranian, model objek berupa objek trigger dan kandang dorong sebagai pencegah terjadinya hal buruk terhadap pomeranian, dan fasilitas lainnya sebagai fasilitas kebutuhan pomeranian secara umum.

\subsection{Saran}

Penelitian ini hanya membahas mengenai model taman dengan pendekatan karakteristik pomeranian secara umum. Aplikasi desain penanaman yang dibahas dalam tulisan ini spesifik untuk kondisi geografis karena umumnya tanaman tidak memiliki pengaruh yang dominan terhadap anjing ras pomeranian.

\section{Daftar Pustaka}

Yusuf, Muri. 2014. Metode Penelitian Kuantitatif,Kualitatif, dan Penelitian Gabungan, Metode Penelitian Kualitatif. Jakarta: PT Fajar Interpratama Mandiri.

AccuWeather, 2016. Iklim Baturiti. Tersedia Online: www.accuweather.com/en/id/baturiti/ (Diakses tanggal 20 Juli 2017).

Nieuwolt, S. 1998. Tropical Climatology, An Introduction to the Climates of the Low Latitude. John Wiley and Sons. New York. 325p.

Kumar, 1997. Fraktur. Tersedia Online: http://duniaveterinary.blogspot.co.id/2 016/02/fraktur-pada-anjing.html. (Diakses Tanggal 07 Agustus 2017)).

Zhang, Winny. 2015 Heat Stroke Pada Anjing. Tersedia Online: http://anjingkita.com /artikel/29327/tandaanjing-kepanasan-overheat.(Diakses Tanggal 07 Agustus 2017)

Perkumpulan Kinologi Indonesia (PERKIN) Bali. 2017. Data Pembiak Pomeranian dan Keseluruhan. Kantor Perkumpulan Kindologi Indonesia Daerah Bali. Jalan Bung Tomo no17.

\section{Informan :}

Puja. Ketut. 2017. Wawancara Mengenai. Kelemahan dan Kebutuhan Anjing Ras kecil bermoncong pesek. Richang. Putu. 2016 Wawancara mengenai. Karakteristik dan Perawatan Spesifik Pomeranian. di kantor Perkumpulan Kinologi Indonesia (PERKIN) Jalan Bung Tomo no17. 